\title{
Quality in Use of an Android-based Mobile Application for Calculation of Bone Mineral Density with the Standard ISO/IEC 25022
}

\author{
Jose Sulla-Torres ${ }^{1}$, Andrea Gutierrez-Quintanilla ${ }^{2}$ \\ Henry Pinto-Rodriguez ${ }^{3}$ \\ Systems Engineering Program \\ Universidad Católica de Santa María, Arequipa, Perú ${ }^{1,2,3}$
}

\author{
Rossana Gómez-Campos ${ }^{4}$, Marco Cossio-Bolaños ${ }^{5}$ \\ Universidad Católica del Maule \\ Talca, Chile ${ }^{4,5}$
}

\begin{abstract}
One of the most critical bone diseases is osteoporosis, which can be evaluated through measurements of bone mineral density. Though there is a lot of commercialized portable about health in general, few are oriented towards bone health and with a lack of user-friendly interface and data management system. This paper presents a mobile application development for the calculation of the Bone Mineral density, which integrates with Google technology. The Mobile-D methodology for the development of mobile applications, due to the sequentially in the processes or stages is used. Bone mineral density (BMD) was calculated using anthropometric regression equations, and an Android-based Mobile Application with Google technology was developed. By using Firebase Authentication and Firebase Storage provided by Google technology, it allows admin to have full control over database management. In short, this mobile application allows the calculation of the BMD of the students and data storage and data uploading to cloud storage for post-processing, online data management system with user authentication. In addition, the Internacional Organization for Standardization / International Electrotechnical Commission (ISO/IEC) 25022 standard was used to evaluate the quality in use of the mobile app, resulting in $93 \%$ of quality in use, this app being able to be used by health professionals for better decision-making.
\end{abstract}

Keywords-Android mobile application; bone mineral density; firebase; software quality; ISO/IEC 25022

\section{INTRODUCTION}

One of the most important diseases related to bones is osteoporosis and is characterized by decreased bone mass density. Thus, the bones become more fragile, and they break more easily [1]. The diagnosis of osteoporosis is made by measuring Bone Mineral Density (BMD), recommended by the World Health Organization [2].

In this context, the BMD assessment is decisive to prevent future bone accidents. BMD measurement is generally performed using double energy X-ray absorptiometry (DXA) scanning equipment, but other proposals allow the BMD to be calculated using anthropometric regression equations [3].

Furthermore, mobile devices are intensifying worldwide and have become an indispensable part of people's daily lives. Mobile applications have proven to be very useful for developing automated solutions to health problems [4] and others associated with proper nutrition to control health conditions [5].

However, of the articles that have been reviewed to date, there are very few works related to bone health and its measurement of BMD, especially in Latin America and oriented towards school children. For this reason, the objective of this article is to develop an Android-based Mobile Application that calculates BMD utilizing anthropometric regression equations of children and adolescents.

For this, the Mobile-D methodology will be followed for the construction of the app; besides, Google's Firebase technology will be used for scalable storage and User Authentication. The validation of the Mobile App will be done using the ISO/IEC 25022 standard to evaluate the quality in use of the mobile app.

The rest of this paper is organized as follows: Section 2 is the background and related work. Section 3 describes the research material and method. Section 4 presents the results and discussion of this research. Finally, this paper is concluded with the future works of this study.

\section{RELATED WORK}

In this section, we discuss previous work in the development of health-oriented mobile applications, then those that are close to the BMD. We also review works that use Firebase services for all of this based on the use of the MobileD Methodology, finally, works that use the ISO / IEC 25022 for the validation of the quality in use.

In the study by Birkhoff and Smeltzer [6], a review was made of the perceptions of health applications focused on the user of mobile devices. The results obtained provided information on the perceptions, experiences, and motivations of users to incorporate health applications for mobile devices in their daily lives when they live with chronic diseases. Likewise, in the study of Baysari and Westbrook [7], they reviewed the human factors that are applied in the design, development, and evaluation of mobile applications developed to favor the issues of coordination of patient-centered care.

Recently Liu et al. [8] present us a mobile application developed on android that allows patient self-diagnosis through the use of a decision tree classification algorithm, this 
application provides medical treatments and information on medications, including opinions of various doctors and related symptoms or causes. These functionalities were tested and evaluated, generating consistent results, and proposing the development of a future version for specialists.

About BMD, a study tested a new approach to help women engage in healthy behaviors related to osteoporosis [9]. This new approach includes beliefs, mechanical skills and abilities, and social facilitation delivered via a cell phone app. The percentage of bone density lost over 12 months was lower than expected. In [10] a mobile health application developed to meet the needs of newly diagnosed women with asymptomatic osteoporosis was tested where the use of an mHealth application is experienced after the diagnosis of osteoporosis and whether the application can help them prepare for decision-making about treatment and support them in selfmanagement of osteoporosis. The application's usability was also tested to find out if any adjustments were necessary before deployment.

About using Mobile-D Methodology, Alnanih et al. [11], they propose a design that is based on the Mobile-D approach by dividing the functionalities of the interactive social, academic application into three versions. The output of the mapping is a set of guidelines that guide the designer through the designing of a mobile application in a distracting environment. In the article by Guevara-Vega et al. [12], they automated the inspection process in the economic activities of a municipality through the development of mobile applications using the Mobile-D methodology, they used the MVC (Model, View, Controller) software architecture and the ScriptCase and Android Studio web service tools. The quality of use of the mobile application was evaluated using the ISO / IEC 25022 standard and the USE questionnaire (usability, satisfaction, ease of use). In the case of Mobile-D, its most significant contribution is the model used for its elaboration, which incorporated developers in the methodological research work itself.

Recently a study presented mobile applications for an inhouse designed home-based heart screening device that integrates with Google technology [13]. By using Firebase Authentication and Firebase Storage provided b Google technology, it allows admin to have full control over database management. From this article, we have taken the idea of using Firebase Database and Firebase Auth to take advantage of data scalability and security.

About quality standard ISO/IEC 25022 standard [14] defines quality in use measures for the characteristics defined in ISO/IEC 25010. These characteristics are then decomposed into sub characteristics and, finally, into measures. In order to be widely adopted, the ISO/IEC 25010 standard is defined generically, applies to any kind of software system. Scenarios demanding quality evaluation of specific systems, or systems with specific features or user needs, require customization [15].

According to the article of Farinango et al. [16], previous studies have been conducted that have demonstrated the effectiveness of information and communication technologies in supporting healthy lifestyle interventions. In particular, personal health record systems (PHR-S) that enhance self-care, essential to support changes in lifestyle. The attributes of quality of efficiency, effectiveness, and user satisfaction were evaluated using metrics defined in the ISO / IEC 25022 standard. From this article, we have considered the use of the standard for the evaluation of the Mobile App.

In the article of Idri and Férnandez-Aleman [17], They evaluate, based on the ISO / IEC 25010 quality standard, the quality of the Mobile Personal Health Records (mPHRs) software, which are mobile applications that allow the organization and storage of patient health data to facilitate administration and access. For both patients and doctors. The results were that functional suitability and reliability are the most used quality characteristics by the apps evaluated [18]. Therefore, these indicators are considered essential for evaluating the quality of the software based on ISO / IEC 25022 standards [19].

As described, most jobs vary on Personal Health Mobile app issues. From the studies studied, we saw that few are oriented to the topic of bone health in children and adolescents. Given the importance of bone health in school children, it is for this reason that in this work, we intend to use the development of the Mobile App together with Google technology validated with ISO / IEC 25022 aimed at school bone health that is little discussed in the literature.

\section{MATERIAL AND METHOD}

To calculate the BMD, data were collected from school children corresponding to anthropometric evaluations carried out on male and female school children between the ages of 6 and 18 from four educational centers in the city of ArequipaPeru. The study was approved by the local ethics committee (UCSM, 2018). It was developed according to Helsinki for humans.

The methodology used to build the Mobile App was Mobile-D in order to achieve rapid development cycles with a small team to achieve functional products in a short time. The methodology consists of the following Phases: Exploration, Initialization, Production, Stabilization and Testing, which are shown in Fig. 1.

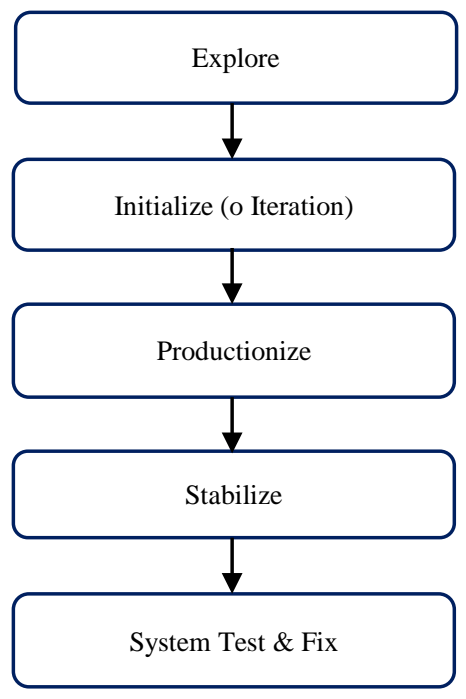

Fig. 1. Phases of the Mobile-D Methodology [20]. 


\section{A. Explore}

The purpose of the exploration phase is to plan and establish the characteristics and concepts of the project. This process is carried out in three stages, shown in Fig. 2.

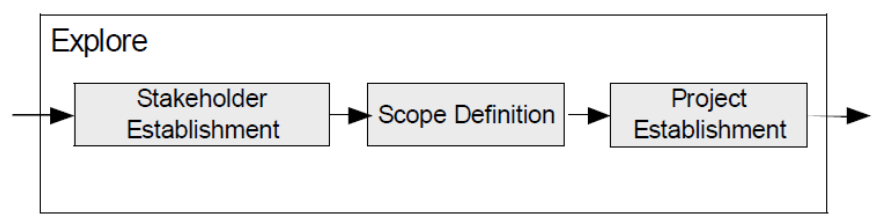

Fig. 2. Explore Phase [20].

- Establishment stakeholder: School children are the objects of direct study, the results of the evaluation are of interest to them, as well as to their parents, just as the teachers want to take control of the evaluations. Health professionals are also interested in the results of the BMD Mobile App.

- Scope Definition: The application must allow User authentication to then enter the anthropometric attributes of the students into the application, then they will be processed to calculate the BMD through anthropometric regression equations that allow determining the degree of osteoporosis that a student has or not and to be displayed on a percentile graph, this must be scalable.

- Project Establishment. The development of the proposal occurs with the execution between the project team of the University and the Educational Centers for the evaluation of BMD in school children using a mobile application.

\section{B. Initialize}

The purpose of this phase is to prepare and identify all the necessary resources. In this phase, it is divided into the following stages, as shown in Fig. 3.

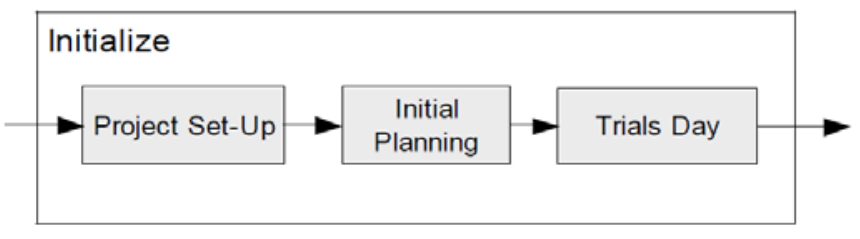

Fig. 3. Initialize Phase [20].

- Proyecto set-up: For the configuration of the environment, we worked with the Android Studio 4.0 development environment, with Firebase Authentication and for data storage with the Firebase Realtime Database of Google technology.

The input and output attributes for the Mobile App were collected from school children and displayed in Table I, Data Dictionary.

- Initial Planning: The initial requirements were specified according to the IEEE 830 standard. The software architecture integrated into the system is based on the layered architecture; It has three main components: mobile interface, application server, and database server. The recommendations of the ISO / IEEE 42010 standard on the Architecture description were used as a guide.

- Trials day: Here, plans were made to verify the readiness of critical development problems, such as the development environment, critical architectural elements, and other external entities of the software to be developed, as well as the communication between the elements and the entities. The output was the results obtained from the execution of the BMD calculation application for school children.

TABLE I. DATA DICTIONARY

\begin{tabular}{|l|l|l|l|}
\hline Attribute & Size & Data Type & Description \\
\hline sSchool & 30 & String & School name \\
\hline sName & 30 & String & Student name \\
\hline iAge & 2 & Int & Student age \\
\hline bGender & 1 & Bool & Gender of the student \\
\hline fWeight & 3.2 & Float & Student Weight \\
\hline fHeight & 1.2 & Float & Student Height \\
\hline fSittingHeight & 1.2 & Float & Sitting Height \\
\hline fForearmLength & 1.2 & Float & Forearm Length \\
\hline fAbdominalCirc & 3.2 & Float & Abdominal Circumference \\
\hline fFemurLength & 1.2 & Float & Femur Length \\
\hline fBmd & 2.2 & Float & Bone mineral density \\
\hline fBmi & 2.2 & Float & Body Mass Indice \\
\hline
\end{tabular}

\section{Productionize}

The production phase aims to implement the required functionality in the product by applying an incremental and iterative development cycle following the good practices of agile methodology [21]. The stages of the Productionize phase are presented in the following Fig. 4.

- Planning: The planning of the requirements analysis, Acceptance tests, planning of iterations, post-iteration tasks were carried out.

The primary function of the Mobile App is to calculate the BMD bone mineral density that was estimated from the equations proposed by Gómez-Campos et al. [22], for both men and women. For each equation, the APVC value, forearm length, and knee diameter are required. Here is the formula:

BMD (men) $=0.605+0.056 * \mathrm{APHV}+0.008 *$ Forearm Length $+0.022 *$ Knee diameter.

BMD (women) $=0.469+0.027 *$ APHV $+0.007 *$ Forearm Length $+0.019 *$ Knee diameter.

Note: To calculate APHV it is necessary to consult Mirwald et al [23]. This equation requires the following data: chronological age, weight, standing height, sitting height, and LP leg length (LP = standing height - sitting height). 
- Working day: It was done following the recommendations of the agile frameworks, choosing the requirements with the highest priority, and implementing them through sprints.

- Release: The functional version was launched incrementally for testing and verification of results, system integration, pre-launch testing, and acceptance testing was performed.

Fig. 5 displays the user authentication screen interface and anthropometric data input to the mobile app for BMD calculation.

\section{Stabilize}

The last integration actions are carried out to ensure that the complete system works correctly. The stabilization phase pattern can be observed in Fig. 6 through the following stages.

Each new addition must work correctly with the rest of the software, and it is done for each new function developed. The use of Firebase Realtime Database ensures the scalability of the data, as well as its adequate access and query operations.

The refactoring of the requirements for defining the type of Inspector, interface refinements, and execution of acceptance tests was carried out.

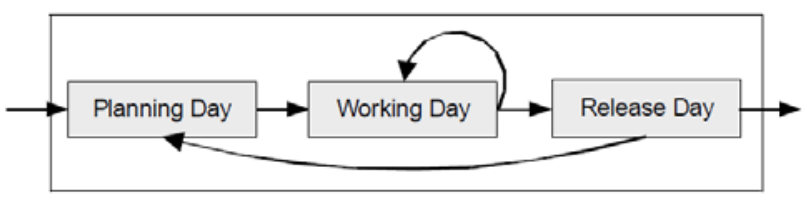

Fig. 4. Productionize Phase [20].

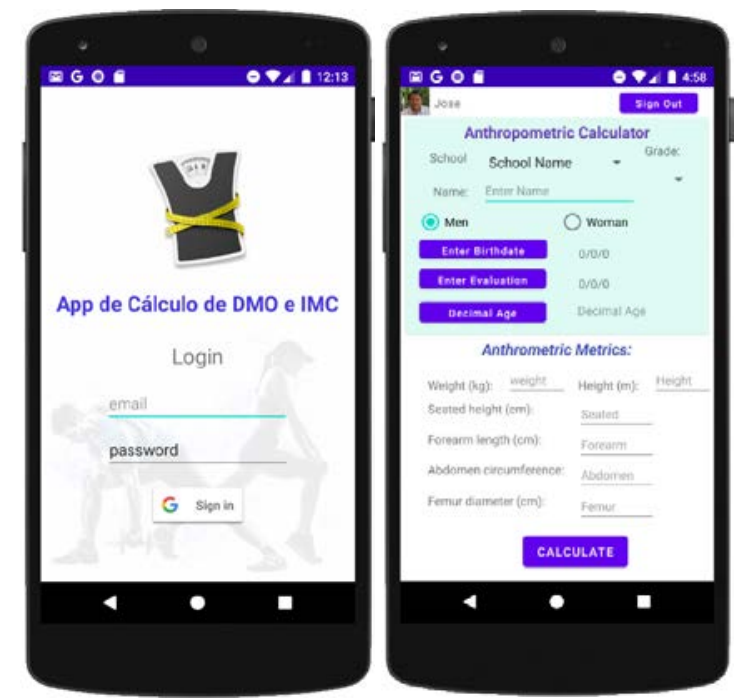

Fig. 5. Interfaces of Authentication and Data Entry of the Mobile App.

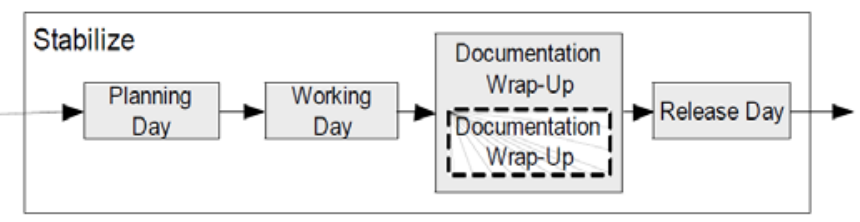

Fig. 6. Stabilize Phase [20].
Fig. 7 shows the storage that is made in the Firebase Realtime Database, which organizes it according to the entered data of the students.

According to the data and the calculation utilizing anthropometric regression equations, the Mobile App obtains the BMD. Fig. 8 shows the result of the BMD calculation that indicates the degree of osteoporosis if the student has or not, and the result is also shown in a percentile graph.

\section{E. System Test}

In this last phase, the complete software is tested to see if the product implements the required functionalities correctly, and to correct the errors found.

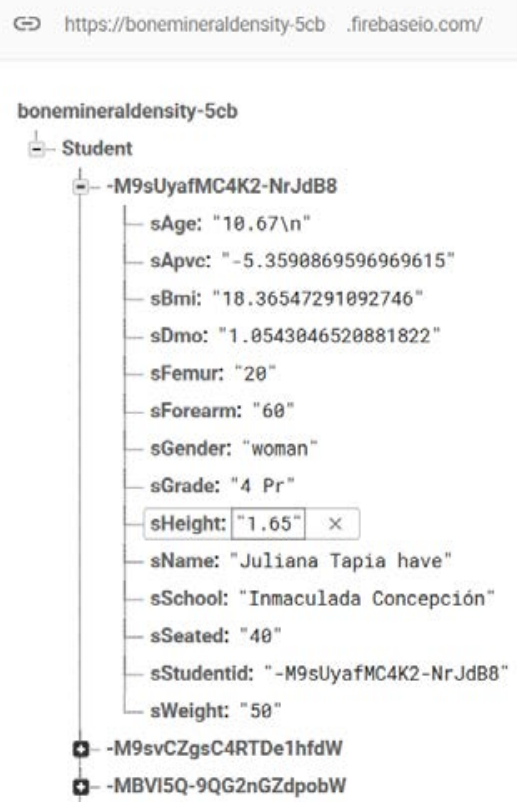

Fig. 7. Data Storage in Firebase Realtime Database.

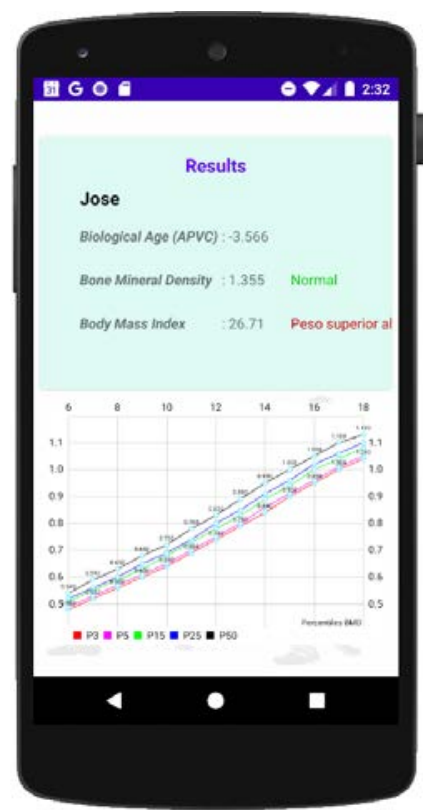

Fig. 8. Result of BMD Calculation in the Mobile App. 
Fig. 9 illustrates the stages of the system test and repair phase.

The evaluation work plan considered the following steps:

- Establish evaluation requirements,

- Specify the evaluation,

- Design the evaluation,

- Run the assessment,

- Conclude the evaluation,

A test plan was made according to the requirements such as Unit, Instrumentation, and UI provided by the Android Studio tool. Once completed, corrections and repairs of possible errors are made.

For the evaluation of the quality of use of the Mobile App, what was proposed by the ISO/IEC 25022 standard was used [12].

The ISO / IEC 25022: 2016 standard contains the following:

- a basic set of measurements for each quality feature in use;

- an explanation of how quality in use is measured.

It provides a suggested set of in-use quality measures to be used with the in-use quality model in ISO / IEC 25010.

Table II shows the Definitions of quality-in-use characteristics as defined by the ISO 25022 standard.

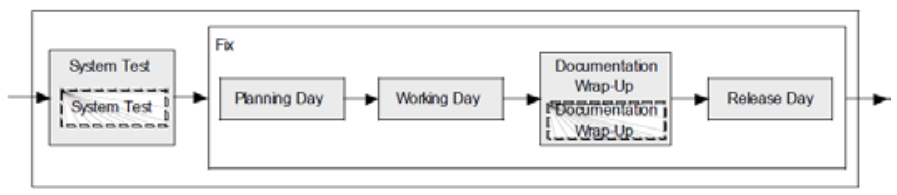

Fig. 9. System Test and Fix Phase [20].

TABLE II. METRICS DEFINED IN THE ISO/IEC 25022

\begin{tabular}{|l|l|}
\hline Characteristic & Definitions \\
\hline Effectiveness & $\begin{array}{l}\text { Accuracy of achieving the expected objective after } \\
\text { performing an action. }\end{array}$ \\
\hline Efficiency & $\begin{array}{l}\text { Resources expended about the accuracy and } \\
\text { completeness with which users achieve goals. }\end{array}$ \\
\hline Satisfaction & $\begin{array}{l}\text { Usefulness: the degree of user satisfaction with the } \\
\text { achievement of the objectives, including the results of } \\
\text { use and the consequences of use. } \\
\text { Trust: the degree to which a user has confidence that a } \\
\text { software product will perform as intended. } \\
\text { Comfort: the degree to which the user is satisfied with } \\
\text { physical comfort. }\end{array}$ \\
\hline Freedom from risk & $\begin{array}{l}\text { Environmental Risk Mitigation: The degree to which a } \\
\text { software product mitigates the potential risk to property } \\
\text { or the environment in the intended contexts of use. }\end{array}$ \\
\hline Context coverage & $\begin{array}{l}\text { Context Completeness: the degree to which a software } \\
\text { product can be used with effectiveness, efficiency, } \\
\text { freedom from risk, and with adequate satisfaction. }\end{array}$ \\
\hline
\end{tabular}

According to the ISO/IEC 25022 metric specification format, Table III presents an example of the Usage metric, belonging to the Usefulness sub-feature with its measurement details.

Once all the phases are finished, it should have a product that can be delivered to the end-user.

TABLE III. Formal SPECIFICATION OF THE QUALITY IN USE METRIC

\begin{tabular}{|c|c|c|c|c|c|}
\hline $\begin{array}{l}\text { Sub- } \\
\text { Charact. }\end{array}$ & Metric & Purpose & Method & $\begin{array}{l}\text { Formul } \\
\text { a }\end{array}$ & Value \\
\hline $\begin{array}{l}\text { Usefulnes } \\
\mathrm{s}\end{array}$ & $\begin{array}{l}\text { Discretionar } \\
\text { y use of } \\
\text { functions }\end{array}$ & $\begin{array}{l}\text { What } \\
\text { percentag } \\
\text { e of users } \\
\text { choose to } \\
\text { use the } \\
\text { system } \\
\text { functions? }\end{array}$ & $\begin{array}{l}\text { Observatio } \\
\mathrm{n}\end{array}$ & $\begin{array}{l}\mathrm{X}=\mathrm{A} / \mathrm{B} \\
\text { where } \\
\mathrm{B}>0 .\end{array}$ & $\begin{array}{l}0 \leq \mathrm{X} \leq \\
1 \\
\text { The } \\
\text { closer } \\
\text { to } 1 \text { is } \\
\text { the } \\
\text { best. }\end{array}$ \\
\hline
\end{tabular}

\section{RESULTS}

The quality metrics in the use of the product based on ISO / IEC 25022: 2016 allow to analyze the characteristics of the interactions in different interest groups with the product. This model is the most recent where the metrics used to measure the quality of product use are effectiveness, efficiency, satisfaction, freedom from risk, and coverage of the software context.

Table IV lists the quality metrics in the use of the software product, as well as its subcategories, the assigned weight (depending on the importance of this study), the value of the measures used, and the result achieved (ISO / IEC 25022: 2016).

TABLE IV. RESULTS OF THE QUALITY ASSESSMENT OF ISO/IEC 25022 (QUALITY IN USE) SOFTWARE

\begin{tabular}{|c|c|c|c|c|c|}
\hline Category & Subcategory & $\begin{array}{l}\text { Weight } \\
\text { categor } \\
\text { y }\end{array}$ & $\begin{array}{l}\text { Weight } \\
\text { sub } \\
\text { categor } \\
\text { y }\end{array}$ & $\begin{array}{l}\text { Measur } \\
\text { e }\end{array}$ & $\begin{array}{l}\text { Result } \\
\text { achieve } \\
\text { d }\end{array}$ \\
\hline \multirow{3}{*}{$\begin{array}{l}\text { Effectivenes } \\
\mathrm{s}\end{array}$} & $\begin{array}{l}\text { Completed } \\
\text { tasks }\end{array}$ & \multirow{3}{*}{$35 \%$} & $20 \%$ & 0.95 & \multirow{3}{*}{$33 \%$} \\
\hline & $\begin{array}{l}\text { Objectives } \\
\text { achieved }\end{array}$ & & $10 \%$ & 0.95 & \\
\hline & Task errors & & $5 \%$ & 0.90 & \\
\hline \multirow{3}{*}{ Efficiency } & Tasks time & \multirow{3}{*}{$30 \%$} & $10 \%$ & 0.90 & \multirow{3}{*}{$28 \%$} \\
\hline & $\begin{array}{l}\text { Time } \\
\text { efficiency }\end{array}$ & & $15 \%$ & 0.95 & \\
\hline & Profitability & & $5 \%$ & 0.95 & \\
\hline \multirow{3}{*}{ Satisfaction } & Usefulness & \multirow{3}{*}{$25 \%$} & $10 \%$ & 0.90 & \multirow{3}{*}{$22 \%$} \\
\hline & Trust & & $10 \%$ & 0.90 & \\
\hline & Comfort & & $5 \%$ & 0.95 & \\
\hline $\begin{array}{l}\text { Freedom of } \\
\text { Risk }\end{array}$ & $\begin{array}{l}\text { Reduction of } \\
\text { environmenta } \\
\text { l } \\
\text { risks }\end{array}$ & $5 \%$ & $5 \%$ & 1.00 & $5 \%$ \\
\hline $\begin{array}{l}\text { Context } \\
\text { coverage }\end{array}$ & $\begin{array}{l}\text { Context } \\
\text { Completenes }\end{array}$ & $5 \%$ & $5 \%$ & 0.95 & $5 \%$ \\
\hline Total & & $100 \%$ & & & $93 \%$ \\
\hline
\end{tabular}


As shown in Table IV, it got 33\% effectiveness, $28 \%$ efficiency, $22 \%$ satisfaction, $5 \%$ freedom of risk, $5 \%$ context coverage adding up to $93 \%$ in quality of use.

\section{CONCLUSIONS}

The Android-based Mobile Application for Calculation of BMD of the students was developed following the steps of the Mobile-D methodology and using Google's Firebase technology, which proved to be very efficient for the massive handling of data.

Tests carried out using the ISO / IEC 25022: 2016 standard resulted in $93 \%$ quality in use concerning the implementation of the system, so it is considered acceptable for use in taking anthropometric measurements and calculating the BMD in school children.

The execution of the mobile app showed that the BMD calculation is obtained in a fast, scalable, and reliable way allowing to determine the degree of osteoporosis that a scholar has or not.

It is widely known that an evaluation of BMD in children and adolescents has high economic costs, however, the use of an anthropometric technique can save time, money and perform a quick evaluation.

The use of this application can serve as an instrument that allows controlling bone development and mineral accumulation during the growth stage. It is a non-invasive alternative that asks to be used daily in the school system.

For future work, this study can be extended the Mobile App with Machine Learning technologies to determine the classification of bone health; Likewise, the calculation of the BMD can be carried out, which would also support the diagnosis of osteoporosis.

This Mobile App can be used as a baseline by specialists in the academic and school health fields for quick decisionmaking regarding the BMD.

\section{ACKNOWLEDGMENTS}

This research has been funded by the Universidad Católica de Santa María, through the project "Proposal of equations and reference values to estimate the bone health of school children and adolescents according to age and sex".

\section{REFERENCES}

[1] M. Li, F. Wan, J. Liu, Q. Hao, and B. Chen, "Analysis of Clinical Risk Factors for Refracture in Osteoporosis," J. Med. Imaging Heal. Informatics, vol. 10, no. 10, pp. 2337-2341, Jul. 2020.

[2] J. A. Kanis, L. J. Melton, C. Christiansen, C. C. Johnston, and N. Khaltaev, “The diagnosis of osteoporosis,” J. Bone Miner. Res., 1994.

[3] F. Alvear-Vasquez, R. Gomez-Campos, P. Pezoa-Fuentes, C. UrraAlbornoz, J. Caceres-Bahamondes, C. Luarte-Rocha, J. Sulla-Torres and M. A. Cossio-Bolaños, "Maximum expiratory flow and handgrip strength predict bone health in children and adolescents," Retos, 2020.

[4] S. K. Choi, B. Yelton, V. K. Ezeanya, K. Kannaley, and D. B. Friedman, "Review of the Content and Quality of Mobile Applications About Alzheimer's Disease and Related Dementias,” J. Appl. Gerontol., 2020.

[5] S. Knez and L. Šajn, "Food object recognition using a mobile device: Evaluation of currently implemented systems," Trends in Food Science and Technology. 2020.
[6] S. D. Birkhoff and S. C. Smeltzer, "Perceptions of Smartphone UserCentered Mobile Health Tracking Apps Across Various Chronic Illness Populations: An Integrative Review,” J. Nurs. Scholarsh., 2017.

[7] M. T. Baysari and J. I. Westbrook, "Mobile Applications for Patientcentered Care Coordination: A Review of Human Factors Methods Applied to their Design, Development, and Evaluation,” Yearbook of medical informatics. 2015.

[8] W. Liu, Y. Liu, L. Pei, and N. Cao, "Design and Implementation of Family Doctor App on Android Platform," in Proceedings - 9th International Conference on Information Technology in Medicine and Education, ITME 2018, 2018.

[9] P. Ryan, R. L. Brown, M. E. Csuka, and P. Papanek, "Efficacy of Osteoporosis Prevention Smartphone App,” Nurs. Res., 2020.

[10] P. Ravn Jakobsen, A. P. Hermann, J. Søndergaard, U. K. Wiil, and J. Clemensen, "Help at hand: Women's experiences of using a mobile health application upon diagnosis of asymptomatic osteoporosis," SAGE Open Med., 2018.

[11] R. Alnanih, N. Bahatheg, M. Alamri, and R. Algizani, "Mobile-d approach-based persona for designing user interface,” Int. J. Adv. Trends Comput. Sci. Eng., vol. 8, no. 5, pp. 2597-2607, Sep. 2019.

[12] C. Guevara-Vega, J. Hernández-Rojas, M. Botto-Tobar, I. GarcíaSantillán, A. Basantes Andrade, and A. Quiña-Mera, "Automation of the Municipal Inspection Process in Ecuador Applying Mobile-D for Android," in Advances in Intelligent Systems and Computing, 2020.

[13] V. H. Goh and Y. W. Hau, "Android-based mobile application for homebased electrocardiogram monitoring device with google technology and bluetooth wireless communication," in 2018 IEEE EMBS Conference on Biomedical Engineering and Sciences, IECBES 2018 - Proceedings, 2019.

[14] ISO/IEC, "ISO/IEC 25022:2016 - Systems and software engineering Systems and software quality requirements and evaluation (SQuaRE) Measurement of quality in use,” ISO/IEC 25022:2016, 2016. [Online]. Available: https://www.iso.org/standard/35746.html. [Accessed: 12-Jul2020].

[15] I. Biscoglio and E. Marchetti, "An experiment of software quality evaluation in the audio-visual media preservation context," in Proceedings - 2014 9th International Conference on the Quality of Information and Communications Technology, QUATIC 2014, 2014.

[16] C. D. Farinango, J. S. Benavides, J. D. Cerón, D. M. López, and R. E. Álvarez, "Human-centered design of a personal health record system for metabolic syndrome management based on the ISO 9241-210:2010 standard,” J. Multidiscip. Healthc., 2018.

[17] A. Idri, M. Bachiri, J. L. Fernandez-Aleman, and A. Toval, "ISO/IEC 25010 Based Evaluation of Free Mobile Personal Health Records for Pregnancy Monitoring," in Proceedings - International Computer Software and Applications Conference, 2017.

[18] A. Idri, M. Bachiri, and J. L. Fernández-Alemán, “A Framework for Evaluating the Software Product Quality of Pregnancy Monitoring Mobile Personal Health Records,” J. Med. Syst., 2016.

[19] H. Nakai, N. Tsuda, K. Honda, H. Washizaki, and Y. Fukazawa, "Initial Framework for Software Quality Evaluation Based on ISO/IEC 25022 and ISO/IEC 25023," in Proceedings - 2016 IEEE International Conference on Software Quality, Reliability and Security-Companion, QRS-C 2016, 2016.

[20] Agile, "Electronics -AGILE - Agile Software Technologies," Software Technologies Research Programme, 2020. [Online]. Available: http://virtual.vtt.fi/virtual/agile/mobiled.html. [Accessed: 01-Jun-2020].

[21] M. C. Sáiz-Manzanares, R. Marticorena-Sánchez, Á. Arnáiz-González, J. F. Díez-Pastor, and S. Rodríguez-Arribas, "Computer Application for the registration and automation of the correction of a functional skills detection scale in early care," in INTED2019 Proceedings, 2019.

[22] R. Gómez-Campos, C. L. Andruske, M. de Arruda, C. Urra Albornoz, and M. Cossio-Bolaños, "Proposed equations and reference values for calculating bone health in children and adolescent based on age and sex," PLoS One, vol. 12, no. 7, p. e0181918, Jul. 2017.

[23] R. L. Mirwald, A. D. G. Baxter-Jones, D. A. Bailey, and G. P. Beunen, "An assessment of maturity from anthropometric measurements," Med. Sci. Sport. Exerc., vol. 34, no. 4, pp. 689-694, 2002. 